\section{Commentary: An ingenious solution born out of necessity}

\author{
Jacob A. Klapper, MD, FACS
}

The description of right-to-left inverted single-lung transplant as reported by Chida and colleagues ${ }^{1}$ is an ingenious feat of technical expertise. The group should be commended for their unconventional approach and the fact that it allowed for them to provide an organ for a patient who otherwise would have remained on the waitlist.

Both the figures and the corresponding videos in the report are very instructive, and I believe it is worth further emphasizing some particular aspects of the procedure. First, although not specifically explained, I would assume that reorientation of the donor lung along the superior-inferior axis facilitated the arterial anastomosis at the top of the pulmonary hilum. Second, preserved length on the recipient pulmonary artery was vital to allowing for positioning the pulmonary artery anastomosis behind the bronchus. Ultimately, the most technically difficult aspect of the operation was the bronchial anastomosis, since lung reorientation meant the authors were required to sew the membranous portion of the recipient bronchus to the cartilaginous portion of the donor and vice versa on the anterior aspect of that anastomosis. Finally, given these complex technical details and the fact that the left chest cavity is often smaller than the right, I would surmise that size matching is of the utmost importance, particularly since with the way the lung is reoriented in the chest, reduction via a middle lobectomy would be extremely difficult.

The classic saying is that "necessity is the mother of invention," and I'm sure that in Japan they do not have the wealth of donors that we possess in the United States.

\footnotetext{
From the Division of Cardiothoracic Surgery, Duke University Medical Center, Durham, NC.

Disclosures: The author reported no conflicts of interest.

The Journal policy requires editors and reviewers to disclose conflicts of interest and to decline handling or reviewing manuscripts for which they may have a conflict of interest. The editors and reviewers of this article have no conflicts of interest.

Received for publication Aug 22, 2020; revisions received Aug 22, 2020; accepted for publication Aug 26, 2020; available ahead of print Sept 15, 2020.

Address for reprints: Jacob A. Klapper, MD, FACS, Division of Cardiothoracic Surgery, DUMC 3954, Durham, NC 27710 (E-mail: Jacob.klapper@ duke.edu).

JTCVS Techniques 2020;4:401

2666-2507

Published by Elsevier Inc. on behalf of The American Association for Thoracic Surgery. This is an open access article under the CC BY-NC-ND license (http:// creativecommons.org/licenses/by-nc-nd/4.0/).

https://doi.org/10.1016/j.xjtc.2020.08.069
}

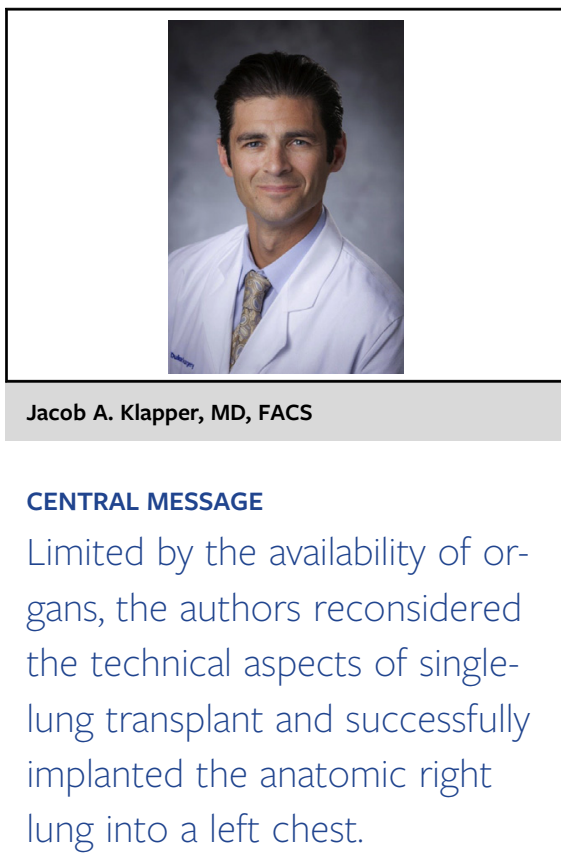

Consequently, the technique that they have applied here will no doubt allow them to offer organs to more of their patients. How much applicability this operative approach has in the United States is debatable. I would argue that, aside from truly extenuating circumstances, most patients in this country should be able to receive an organ that is anatomically correct. That said, even though I don't envision widespread adoption of this technique in the West, this case report is just another example of what a dynamic field lung transplant has been and continues to be.

\section{Reference}

1. Chida M, Araki O, Karube Y, Maeda S. Right-to-left inverted single lung transplantation. J Thorac Cardiovasc Surg Tech. 2020;4:395-7. 